\title{
Modeling of the Chemico-Physical Process of Protonation of Molecules Entailing Some Quantum Chemical Descriptors
}

\author{
Sandip K. Rajak, Nazmul Islam, Dulal C. Ghosh" \\ Department of Chemistry, University of Kalyani, Kalyani, India \\ E-mail:"dcghosh1@rediffmail.com \\ Received May 27, 2011; revised July 25, 2011; accepted August 6, 2011
}

\begin{abstract}
Relying upon the basic tenets of scientific modeling, an ansatz for the evaluation of proton affinity of molecules are evolved in terms of a four component model. The components of the model chosen are global descriptors like ionization energies, global softness, electronegativity and electrophilicity index. These akin quantum mechanical descriptors of atoms and molecules are linked with the charge rearrangement and polarization that occur during the physico-chemical process of protonation of molecules. The suggested ansatz is invoked to compute the protonation energy of as many as 43 compounds of diverse physico-chemical nature viz, hydrocarbons, alcohols, carbonyls, carboxylic acids, esters, aliphatic amines and aromatic amines. A detailed comparative study of theoretically evaluated protonation energies of the above mentioned molecules vis-à-vis their corresponding experimental counterparts reveals that there is a close agreement between the theory and experiment. Thus the results strongly suggest that the proposed modeling and the ansatz for computing PA, the proton affinity, of molecules for studying the physico-chemical process of protonation may be valid proposition.
\end{abstract}

Keywords: Physico-Chemical Process of Protonation, Proton Affinity, Conceptual Density Functional Descriptors, Commonality between Density Functional Descriptors and Proton Affinity, Muliti-Linear Regression Model

\section{Introduction}

The protonation reaction or the physico-chemical process of protonation is ubiquitous in almost all the areas of chemistry and biochemistry [1-5]. The majority of chemical reaction occurs in acid medium. The chemical process of protonation is fundamental first step of many chemical rearrangements, and enzymatic reactions [4]. The resulting protonated molecule is frequently a pivotal intermediate that guides the succeeding steps of the overall process. The knowledge of the intrinsic basicity and the site of protonation of a compound is central for the understanding of the mechanism of chemical reactions. The legend proton affinity is defined as the negative of the enthalpy change of a protonation reaction at the standard conditions. The gas-phase proton affinities are a quantitative measure of the intrinsic basicity of a molecule [6]. The study of thermochemistry of the proton transfer reaction in the gas phase is well-known ex- periment of acid-base reaction [7]. Dynamics of proton transfer is also important for ionization processes in mass spectroscopy [8]. Basicity is defined [9] as the tendency of a molecule, $\mathrm{B}$, to accept a proton, $\mathrm{H}^{+}$, in the following Base-Acid (Proton) adduct $\mathrm{BH}^{+}$formation reaction

$$
\mathrm{B}+\mathrm{H}^{+}=\mathrm{BH}^{+}-\mathrm{PA}
$$

where PA is the proton affinity of the base $\mathrm{B}$.

This concept of basicity was generalized further and freed from reference to a specific acid $\left(\mathrm{H}^{+}\right)$by Lewis [10]. During the physico-chemical process of protonation, electronic charge is soaked by the proton from the entire skeleton of the molecule. As a result, all the structural parameters i.e. bond lengths and bond angles, and other charge dependent physical properties like the polarizability and the dipole etc are affected. A plethora of information has appeared on the study of this important chemicophysical process $[6,7]$.

Although, experimentally the proton affinity can be 
determined by several techniques like the measurement of the heats of formation [5] of the species involved in the adduct formation reaction, by mass spectroscopic measurement techniques [7-9,11] and by the measurement of the ionization thresholds [7]. The "acid-base adducts" are not always stable and/or does not exist in all cases and also it is well known [12] that the experimental determination of the proton affinities of molecules is not easy always. For this reason, in recent years, much emphasis has been given to the calculation of proton affinities through some quantum mechanical and its young branch, the density functional theoretical models [13-17].

It is now established [18] that the $a b$ initio quantum mechanical approaches and its numerous variants are very successful in providing reliable values of proton affinity and gas phase basicity for small molecules. However, due to the reason of heavy computational cost , application of $a b$ initio methods for the estimation of proton affinities is still impractical for larger molecules [19]. It is also recognized [20] that the popular semi empirical methods such as AM1, MNDO and PM3 etc are not that reliable in calculating proton affinities. Although there are some attempts of modeling to compute protonation energy for specific groups of compounds [6,21-26], but fact remains that no universal model has been, so far, put forward subsuming the energetic effects necessarily appearing in the physico-chemical process of protonation as a substitute for experimental or theoretical measurement of the energy of protonation.

Currently the conceptual density functional theory [27-44] of chemical reactivity have introduced many descriptors, global and local, like electronegativity, hardness, softness, fukui functions, electrophilicity index etc in theoretical chemistry. Such descriptors have made serious inroad in science and opened a new paradigm of chemical thinking, modeling and computation [27-44].

In this work, we have developed a model for the evaluation of proton affinity in terms of some akin conceptual reactivity descriptors which can be conceptually linked and associated with the physico-chemical process of protonation. The akin descriptors are the ionization energy (I), the global softness(S), the electronegativity $(\chi)$, and the global electrophilicity index $(\omega)$.

\subsection{The Physico-Chemical Process of Protonation}

In the terminology classification of chemical reaction according to the reagent and the substrate, proton is an electrophile. In the physico-chemical process of protonation, when a proton dynamically approaches towards a nucleophile from a long distance it is attracted by the electron cloud of the molecule. The proton acting as an electrophile soaks the electron density from the entire skeleton of the nucleophile [45]. As a result, the electron cloud of the nucleophile is redistributed and remains under the influence of the electrophile, the proton. In some circumstances, the proton fixes at a site of lone pair, if available, in the molecule. However, if there is no lone pair in the structure of the molecule, the proton remaining attached to the sphere of the charge cloud of the molecule. The polarizing power of the proton induces a physical process of structural and energetic changes in the molecule and the effect is expected to be at its maximum at the gas phase of the molecule. Thus, the gasphase basicity is certainly the ideal revelator of the structural and energetic characteristics of the molecular protonation process.

\subsection{The Physico-Chemical Process of Protonation Entailing the Ionization Energy, the Electronegativity, the Chemical Hardness, the Softness, and the Electrophilicity Index}

In order to suggest a mathematical modeling of computing the protonation energy of molecules involving the above akin theoretical descriptors that may be associated and directly linked with the physico-chemical process of protonation, we depict the glimpses of the role of each descriptor in the process separately viz.

1) The ionization energy (I)

This is a fundamental descriptor of the chemical reactivity of atoms and molecules. High ionization energy indicates high stability and chemical inertness and small ionization energy indicates high reactivity of the atoms and molecules [46]. Mills et al. [47] discovered a linear relationship between the proton affinity and the additive inverse of the ionization energies of molecules.

\section{2) Electronegativity $(\chi)$}

Electronegativity though defined in many different ways, the most logical and rational definition of it is the electron holding power of the atoms or molecules. Electronegativity is defined and measured as the power (force) with which the valence electron of an atom is held by its screened nuclear charge. The more electronegative elements hold electrons more tightly and the less electronegative elements hold less tightly. Lohr [48] has discussed the physico-chemical process of protonation from a deeper insight and discovered the important relationship between the protonation and electronegativity. $\mathrm{He}$ [48] further went to conclude that there is a protonic counter part of electronegativity as a organizing principle of acidity and basicity. However, the inverse relationship between the electronegativity and protonation process and associated energetic effect is straight forward. 


\section{3) Global Softness ( $S$ )}

The softness is in fact the inverse concept of hardness, a fundamental descriptor of the stability and reactivity of atoms and molecules. It is apparent that the chemical hardness fundamentally signifies the resistance towards the deformation or polarization of the electron cloud of the atoms, ions or molecules under small perturbation of chemical reaction. The softness is simply the reciprocal of the hardness. Thus the general operational significance of the hard-soft chemical species may be understood in the following statement. If the electron cloud is strongly held by the nucleus, the chemical species is "hard" but if the electron cloud is loosely held by the nucleus the system is "soft" $[40,49]$. Hence the polarization process associated with protonation should be directly controlled by the softness of the molecule. Or in other words, the energetic effect associated with the protonation should be directly proportional to the softness of the molecule.

\section{4) Electrophilicity Index ( $\omega)$}

In reference to nucleophilic-electrophilic, acid-base or donor-acceptor reaction, the electrophilicity index $[50,51]$ of atoms and molecules seems to be an absolute and fundamental property of such chemical species because it signifies the energy lowering process on soaking electrons from the donors. This tendency of charge soaking and energy lowering must emanate and develop from the attraction between the soaked electron density and screened nuclear charge of the atoms and molecules.

As the process of electron soaking by proton continues, the accumulated electron density will, however, shield the proton. However, the electrophilicity of the substrate will oppose the charge soaking by the proton during the physico-chemical process of protonation and hence the protonation is hindered by the electrophilicity and hence protonation energy should bear an inverse relationship with electrophilicity index.

\section{The Modeling of the Physico-Chemical Process of Protonation and Algorithm for Computing the Proton Affinity of the Molecules}

The descriptors like the ionization process of atoms and molecules, the physical property like hardness, softness, the electronegativity and the electrophilicity have close relation i.e. akin with each other in their operational significance and origin.

We have tried to posit above that the physico-chemical process of protonation can be linked to the above akin descriptors -the ionization process, the hardness, softness, electronegativity and electrophilicity. Recently, we [52-61] have published good number of papers where we have discussed that the three descriptors, the electronegativity, the hardness and the electrophilicity index of atoms and molecules are fundamentally qualitative per se and operationally the same. All these three descriptors represent the attraction of screened nuclei towards the electron pair/bond. Thus, we can safely and reasonably conclude that the proton affinity and the three descriptors have inverse relationship.

Thus, since the above four parameters have dimension of energy and can be linked to the process of charge rearrangement and polarization during the physico-chemical process of protonation, they can be components of a probabilistic scientific modeling of proton affinity. The physico-chemical process of protonation has direct link to the charge polarization and alteration of electron distribution in the molecule.

The proton affinity or the ability of donating the lone pair of a Lewis base and the ability for the deformation of electron cloud of a species, the softness, and /or the tendency of the molecule to lose electron, the ionization potential, are fundamentally similar in physical appearance stemming from the attraction power of the nuclei of the atoms forming the molecule. The softness, the ionization energy, the electronegativity (chemical potential) and the electrophilicity index have direct link to the process of polarization and transfer of charge from a substrate and hence control the energetic effect- the protonation energy. Considering all the above mentioned fundamental nature of the physico-chemical process of protonation and its probable relationship with the quantum mechanical descriptors, we suggest an ansatz for the computation of the proton affinity in terms of these theoretical descriptors. The physico-chemical process and the energetic effect must entail the above stated four parameters. To derive an explicit relation to compute the proton affinity in terms of the above stated descriptors, we suggest explicit inter relationships between the protonation energy and the descriptors relying upon their response towards the protonation.

$$
\begin{aligned}
& \mathrm{PA} \infty(-\mathrm{I}) \\
& \mathrm{PA} \infty \mathrm{S} \\
& \mathrm{PA} \infty 1 / \chi \\
& \mathrm{PA} \infty 1 / \omega
\end{aligned}
$$

Combining the above four relations we get,

$$
\mathrm{PA}=\mathrm{C}+\mathrm{C}_{1}(-\mathrm{I})+\mathrm{C}_{2} S+\mathrm{C}_{3}(1 / \chi)+\mathrm{C}_{4}(1 / \omega)
$$

where $\mathrm{PA}$ is proton affinity, $\mathrm{C}, \mathrm{C}_{1}, \mathrm{C}_{2}, \mathrm{C}_{3}$, and $\mathrm{C}_{4}$ are the constants I is ionization energy, $\mathrm{S}$ is global softness, $\chi$ is the electronegativity and $\omega$ is the global electrophilicity index of the molecule. 


\section{Method of Computation}

Ab initio Hartree-Fock SCF method and the Koopmans' theorem are invoked to compute the ionization potential (I) and electron affinity(A), which in turn, are used in computing the descriptors invoked in this studies.

According to Koopmans' theorem the ionization potential (I) and the electron affinity (A) are computed as follows:

$$
\begin{aligned}
& \mathrm{I}=-\varepsilon_{\text {HOMO }} \\
& \mathrm{A}=-\varepsilon_{\text {LUMO }}
\end{aligned}
$$

where $\varepsilon_{\text {HOMO }}$ and $\varepsilon_{\text {LUMO }}$ are the orbital energies of the highest occupied and the lowest unoccupied orbitals.

Parr et al. $[40,41,44]$ defined the chemical potential, $\mu$, electronegativity, $\chi$, and hardness, $\eta$, in the framework of density functional theory, DFT as

$$
\begin{gathered}
\mu=(\partial \mathrm{E} / \partial \mathrm{N})_{\mathrm{V}(\mathrm{r})}=-\chi=(\mathrm{I}+\mathrm{A}) / 2 \\
\eta=1 / 2[\partial \mu / \partial \mathrm{N}]_{\mathrm{V}(\mathrm{r})}=1 / 2\left[\partial^{2} \mathrm{E} / \partial \mathrm{N}^{2}\right]_{\mathrm{V}(\mathrm{r})}=1 / 2(\mathrm{I}-\mathrm{A})(10)
\end{gathered}
$$

where $\mathrm{E}, \mathrm{N}, \mathrm{v}(\mathrm{r}), \mathrm{I}$ and $\mathrm{A}$ are the energy, the number of electrons, the external potential, the ionization energy and the electron affinity of a chemical system respectively.

Softness is a reactivity index and is defined as the reciprocal of hardness

$$
\mathrm{S}=(1 / \eta)
$$

Parr et al. [36] defined electrophilicity index ( $\omega)$ as

$$
\omega=(\mu)^{2} /(2 \eta)
$$

In this study we have taken some hydrocarbons in Set-1, alcohols, carbonyls, carboxylic acids and esters in Set-2, aliphatic amines in Set-3 and aromatic amines in Set-4. The molecules are so chosen whose experimental protonation [7,62-65] energy are known. The PQS Mol 1.2 - 20-win software [66] has been used to calculate the global descriptors using the $a b$ initio Hartree-Fock SCF method with 6 - $31 \mathrm{~g}$ basis set. The geometry optimization technique is adopted. The ionization energy, the electronegativity, the global softness, and the global electrophilicity index of the molecules are computed by invoking the Koopmans' theorem and Equation (7), Equation (9), Equation (11) and Equation (12) respectively.

A multi linear regression analysis [67] is performed using Minitab 15 [68] to compute the correlation coefficients $\mathrm{C}, \mathrm{C}_{1}, \mathrm{C}_{2}, \mathrm{C}_{3}$ and $\mathrm{C}_{4}$ by plotting experimental PA along the abscissa and the values of the quantum mechanical descriptors along the ordinate. The computed correlation coefficients $\mathrm{C}, \mathrm{C}_{1}, \mathrm{C}_{2}, \mathrm{C}_{3}$ and $\mathrm{C}_{4}$, for the Set 1 , Set 2, Set-3 and Set-4 are tabulated in Table 1.
Thereafter, we have computed the P.A's of four sets of molecules invoking the suggested ansatz, Equation (6), and putting the quantum mechanical descriptors and the respective correlation coefficients of each set of molecules under our study. The comparative study of theoretically evaluated and experimentally determined PA's of the Set 1 - Set 4 is performed in the Tables 2-5 respectively.

Table 1. Correlation coefficients and $R^{2}$ value for the Set 1 , Set 2, Set 3 and Set 4 .

\begin{tabular}{ccccccc}
\hline Sets & $\mathrm{C}$ & $\mathrm{C}_{1}$ & $\mathrm{C}_{2}$ & $\mathrm{C}_{3}$ & $\mathrm{C}_{4}$ & $\mathrm{R}^{2}$ \\
\hline 1 & 450 & 18.0 & 24100 & -40539 & 8019 & 0.992 \\
2 & -113 & -4.66 & -1810 & 3561 & -705 & 0.818 \\
3 & 17.1 & 0.666 & -0.1 & -0.1 & -0.15 & 0.995 \\
4 & -129 & +7.94 & 147 & 167 & -11.1 & 0.916 \\
\hline
\end{tabular}

Table 2. Experimental P.A (eV), calculated P.A (eV) and $\mathbf{R}^{2}$ for the Set 1.

\begin{tabular}{lccc}
\hline Molecule & Experimental P.A & Calculated P.A & $\mathrm{R}^{2}$ \\
\hline Methane & 5.63294 & 6.01418 & 0.99 \\
Ethane & 6.17932 & 6.56332 & \\
Propane & 6.48286 & 6.83883 & \\
Butane $^{*}$ & 6.83237 & 7.07331 & \\
Isobutane $^{*}$ & 7.02491 & 7.34303 & \\
Pentane $^{*}$ & 6.86533 & 7.13276 & \\
Hexane $^{*}$ & 7.01407 & 7.37095 & \\
\hline
\end{tabular}

*P.A calculated by Wróblewski et al. ${ }^{45}$

Table 3. Experimental P.A (eV), calculated P.A (eV) and $R^{2}$ for the Set 2.

\begin{tabular}{lccc}
\hline \multicolumn{1}{c}{ Molecule } & Experimental P.A & Caculated P.A & $\mathrm{R}^{2}$ \\
\hline Formaldehyde & 7.38916 & 7.90889 & 0.817 \\
Formic acid & 7.68837 & 8.13938 & \\
Methanol & 7.81846 & 8.57263 & \\
Ketene & 8.55564 & 8.96532 & \\
Acetaldehyde & 7.9659 & 8.34277 & \\
Ethanol & 8.04829 & 8.57857 & \\
Acetic acid & 8.12201 & 8.55023 & \\
Acetone & 8.41254 & 8.90774 & \\
Propanol & 8.15236 & 8.47112 & \\
Propionic acid & 8.26077 & 8.50291 & \\
Methyl acetate & 8.28679 & 8.61904 & \\
Butanol & 8.17838 & 8.46674 & \\
\hline
\end{tabular}


Table 4. Experimental P.A (eV), calculated P.A (eV) and $R^{2}$ for the Set 3.

\begin{tabular}{lccc}
\hline \multicolumn{1}{c}{ Molecule } & Experimental P.A & Caculated P.A & $\mathrm{R}^{2}$ \\
\hline $\mathrm{NH}_{3}$ & 8.846181 & 8.860042 & 0.995 \\
$\mathrm{CH}_{3} \mathrm{NH}_{2}$ & 9.284153 & 9.341572 & \\
$\mathrm{CH}_{3} \mathrm{CH}_{2} \mathrm{NH}_{2}$ & 9.409908 & 9.399806 & \\
$\left(\mathrm{CH}_{3}\right)_{2} \mathrm{CHNH} \mathrm{HH}_{2}$ & 9.47929 & 9.499455 & \\
$\left(\mathrm{CH}_{3}\right)_{2} \mathrm{NH}$ & 9.566017 & 9.583402 & \\
$\left(\mathrm{CH}_{3}\right)_{3} \mathrm{CNH}_{2}$ & 9.57469 & 9.596479 & \\
$\left(\mathrm{CH}_{3}\right)_{3} \mathrm{~N}$ & 9.761153 & 9.794852 & \\
\hline
\end{tabular}

Table 5. Experimental P.A (eV), calculated P.A (eV) and $R^{2}$ for the Set 4 .

\begin{tabular}{|c|c|c|c|}
\hline Molecules & $\begin{array}{c}\text { Experimental P.A } \\
(\mathrm{eV}))\end{array}$ & $\begin{array}{c}\text { Calculated P.A } \\
(\mathrm{eV})\end{array}$ & $\mathrm{R}^{2}$ \\
\hline $3-\mathrm{H}_{3} \mathrm{C}_{6} \mathrm{H}_{4} \mathrm{~N}\left(\mathrm{C}_{2} \mathrm{H}_{5}\right)_{2}$ & 9.925935 & 9.722904 & 0.91 \\
\hline $4-\mathrm{H}_{3} \mathrm{C}_{6} \mathrm{H}_{4} \mathrm{~N}\left(\mathrm{C}_{2} \mathrm{H}_{5}\right)_{2}$ & 9.912926 & 9.706435 & \\
\hline $\mathrm{C}_{6} \mathrm{H}_{5} \mathrm{~N}\left(\mathrm{C}_{3} \mathrm{H}_{7}\right)_{2}$ & 9.912926 & 9.673925 & \\
\hline $\mathrm{C}_{6} \mathrm{H}_{5} \mathrm{~N}\left(\mathrm{CH}_{3}\right)\left(\mathrm{C}_{2} \mathrm{H}_{5}\right)$ & 9.84788 & 9.522402 & \\
\hline $\mathrm{C}_{6} \mathrm{H}_{5} \mathrm{NH}\left(\mathrm{C}_{2} \mathrm{H}_{5}\right)$ & 9.618053 & 9.592654 & \\
\hline $\mathrm{C}_{6} \mathrm{H}_{5} \mathrm{NHCH}_{3}$ & 9.457608 & 9.44481 & \\
\hline $\mathrm{C}_{6} \mathrm{H}_{5} \mathrm{CH}_{2} \mathrm{NH}_{2}$ & 9.401235 & 8.976198 & \\
\hline $2-(\mathrm{OH}) \mathrm{C}_{6} \mathrm{H}_{4} \mathrm{NH}_{2}$ & 9.28849 & 9.197386 & \\
\hline 3-(OH) $\mathrm{C}_{6} \mathrm{H}_{4} \mathrm{NH}_{2}$ & 9.28849 & 9.197251 & \\
\hline $4-\mathrm{CH}_{3} \mathrm{C}_{6} \mathrm{H}_{4} \mathrm{NH}_{2}$ & 9.266808 & 9.06326 & \\
\hline $3-\mathrm{CH}_{3} \mathrm{C}_{6} \mathrm{H}_{4} \mathrm{NH}_{2}$ & 9.253799 & 9.04584 & \\
\hline $3-\mathrm{CH}_{3} \mathrm{C}_{6} \mathrm{H}_{4} \mathrm{~N}\left(\mathrm{CH}_{3}\right)_{2}$ & 9.253799 & 9.044886 & \\
\hline $1,2-\mathrm{C}_{6} \mathrm{H}_{4}\left(\mathrm{NH}_{2}\right)_{2}$ & 9.22778 & 9.031081 & \\
\hline 4- $\mathrm{ClC}_{6} \mathrm{H}_{4} \mathrm{NH}_{2}$ & 9.045653 & 8.720894 & \\
\hline $3-\mathrm{BrC}_{6} \mathrm{H}_{4} \mathrm{NH}_{2}$ & 9.023971 & 8.683775 & \\
\hline 4- $\mathrm{FC}_{6} \mathrm{H}_{4} \mathrm{NH}_{2}$ & 9.023971 & 8.763088 & \\
\hline $3-\mathrm{CF}_{3} \mathrm{C}_{6} \mathrm{H}_{4} \mathrm{NH}_{2}$ & 8.854853 & 8.674228 & \\
\hline
\end{tabular}

For better visualization of the comparative study, the results of the theoretically computed and experimentally determined proton affinities of the Set 1 - Set 4 are depicted in the Figures 1-4 respectively.

\section{Results and Discussion}

A deeper look on the Table 2 and Figure 1 (for Set 1), and the Table 4 and Figure 3 (for Set 3) reveals that there are excellent correlation between the theoretically computed proton affinities of the seven hydrocarbons
(Set 1) and seven aliphatic amines (Set 2) respectively. The $\mathrm{R}^{2}$ value for the correlation of Setl and Set 3 are 0.99 and 0.995 respectively. A close look at the Figure 1 and Figure 3 reveals that the two sets of PA's-experimental and theoretical of the two groups of molecules are so close to each other that one curve just superimposes upon the other.

A look at the Table 3 and Figure 2 (for Set 2), and Table 5 and Figure 4 (for Set 4) reveals that there is fairly a good correlation between the theoretically computed and experimentally determined proton affinities of as many as twelve compounds containing alcohols, carbonyls, carboxylic acids and esters(Set 2), and seventeen aromatic amines (Set 4) respectively. The $\mathrm{R}^{2}$ value for correlation of Set 2 and Set 4 are 0.817 and 0.91 respectively.

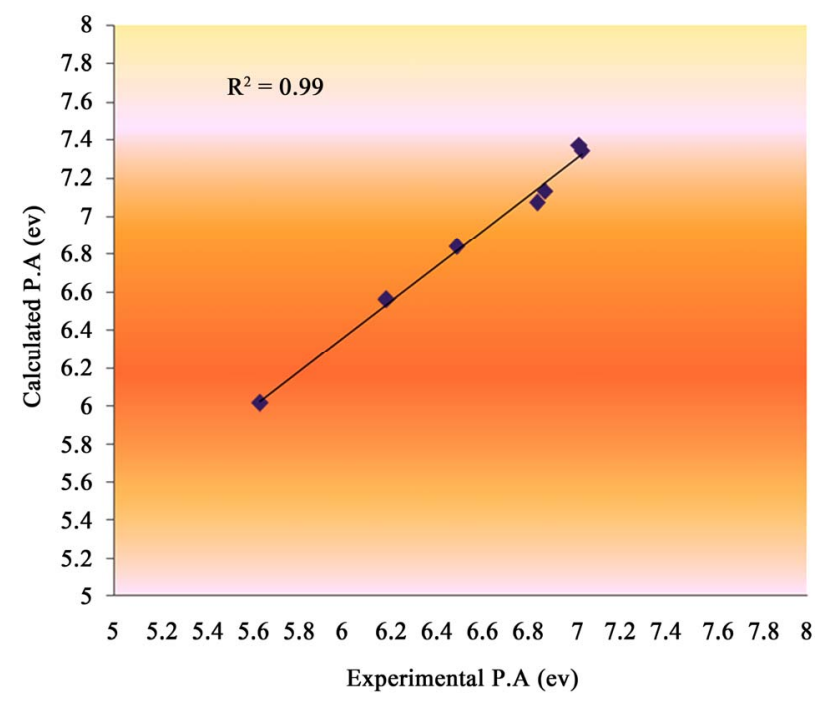

Figure 1. Plot of calculated P.A Vs Experimental P.A and P.A calculated by Wróblewski et al. for Set 1 .

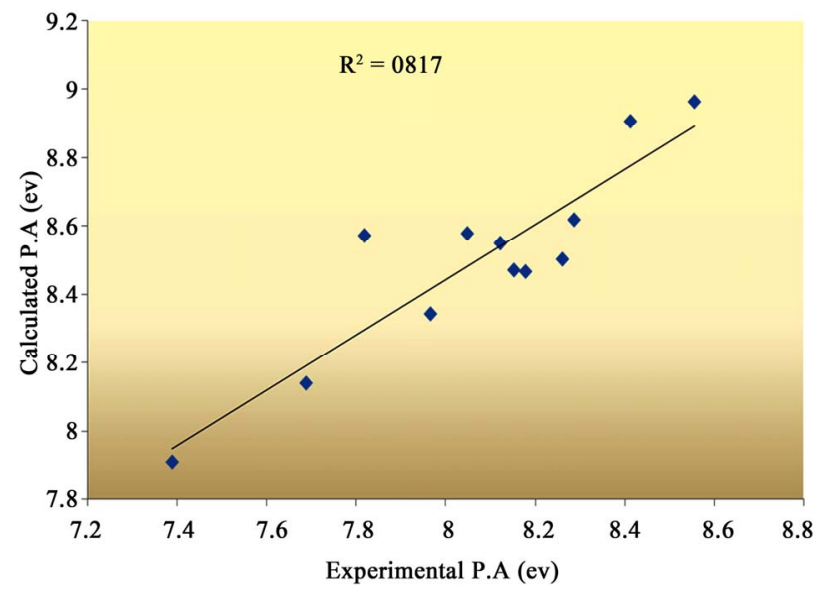

Figure 2. Plot of calculated P.A Vs experimental P.A for Set 


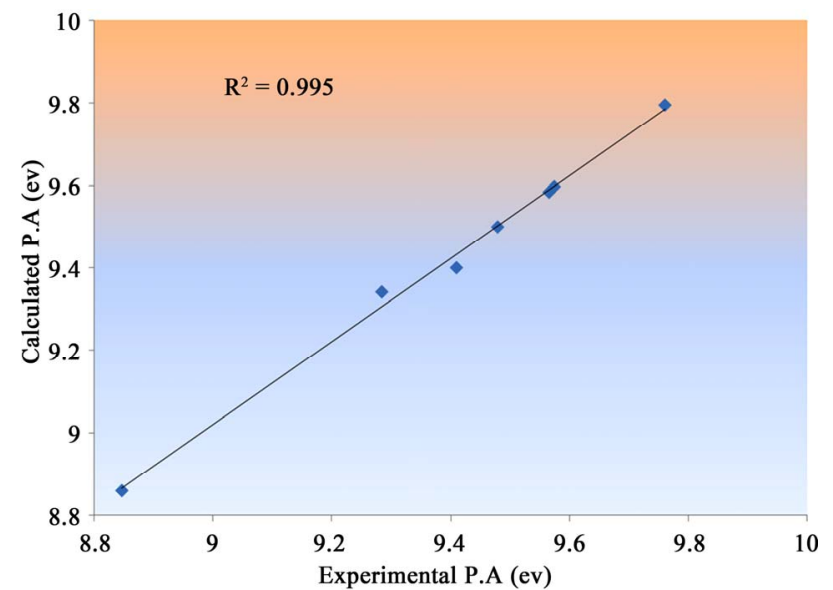

Figure 3. Plot of calculated P.A Vs experimental P.A for Set 3.

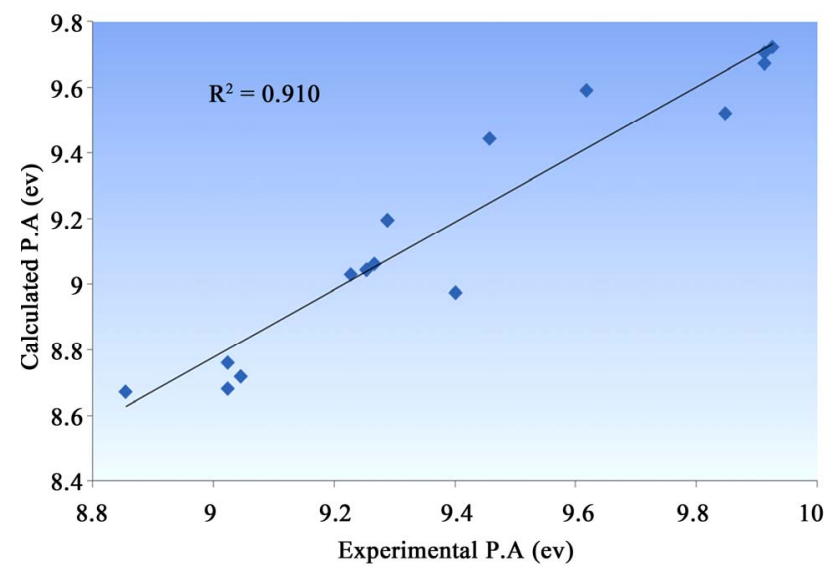

Figure 4. Plot of calculated PA Vs experimental P.A for Set 4.

\section{Conclusions}

In this work, we have presented a scientific model for the evaluation of protonation energy of molecules in terms of four quantum theoretical descriptors - the ionization energy, the global softness, the electronegativity, and the global electrophilicity index as components. As a basis of scientific modeling, we have posited that these akin theoretical descriptors describe the charge rearrangement and polarization that occur during the physico-chemical process of protonation. The test molecules chosen are of diverse physico-chemical nature. A validity test of the model is performed by comparing the protonation energies of as many as 43 molecules computed using the ansatz proposed in this work vis-à-vis their corresponding experimental counterparts. The close agreement between the theoretically evaluated and experimentally determined PA's, the proton affinities, strongly suggests that the four component modeling in terms of quantum chemical descriptors having link with the physicochemical process of protonation is efficacious and the suggested ansatz for computing P.A of molecules and hypothesis relied upon are scientifically acceptable.

\section{References}

[1] R. Stewart, "The Proton: Appellation to Organic Chemistry," Academic Press, New York, 1985.

[2] F. A. Carrol, "Perspectives on Structure and Mechanism in Organic Chemistry,” Brooks-Cole, New York, 1998.

[3] J. Zhao and R. Zhang, "Proton Transfer Reaction Rate Constants between Hydronium Ion $\left(\mathrm{H}_{3} \mathrm{O}^{+}\right)$Andvolatile Organic Compounds," Atmospheric Environment, Vol. 38, No. 14, 2004, pp. 2177-2185. doi:10.1016/j.atmosenv.2004.01.019

[4] R. A. Kennedy, Ch. A. Mayhew, R. Thomas and P. Watts, "Reactions of $\mathrm{H}_{3} \mathrm{O}^{+}$with a Number of Bromine Containing Fully and Partially Halogenated Hydrocarbons," International Journal of Mass Spectrometry, Vol. 223-224, 2003, pp. 627-637. doi:10.1016/S1387-3806(02)00934-X

[5] G. Bouchoux, "Gas-Phase Basicities of Polyfunctional molecules Part 1: Theory and Methods," Mass Spectrometry Reviews, Vol. 26, No. 6, 2007, pp. 775-835. doi:10.1002/mas.20151

[6] C. A. Deakyne, "Proton Affinities and Gas-Phase Basicities: Theoretical Methods and Structural Effects," International Journal of Mass Spectrometry, Vol. 227, No. 3, 2003, pp. 601-616. doi:10.1016/S1387-3806(03)00094-0

[7] S. G. Lias, J. F. Liebman and R. D. Levine, "Evaluated Gas Phase Basicties and Proton Affinityies of Molecules; Heat of Formation of Protonated Molecules," Journal of Physical and Chemical Reference Data, Vol. 13, No. 3, 1984, pp. 695-808. doi:10.1063/1.555719

[8] A. Hansel, N. Oberhofer, W. Lindinger, V. A. Zenevich and G. B. Billing, "Vibrational Relaxation of $\mathrm{NO}^{+}(\mathrm{v})$ in Collisions with $\mathrm{CH}_{4}$ : Experimental and Theoretical Studies," International Journal of Mass Spectrometry, Vol. 185-187, 1999, pp. 559-563. doi:10.1016/S1387-3806(98)14156-8

[9] J. N. Bronsted, "Einige Bemerkungen üBer den Begriff der saüRen und Basen," Recl Trav chim Pays-Bas, Vol. 42, 1923, pp. 718-728.

[10] G. N. Lewis, "Valence and the Structure of Atoms and Molecules," Chemical Catalog, New York, 1923.

[11] M. Meot-Ner, "Ion Thermochemistry of Low-Volatility Compounds in the Gas Phase. 2. Intrinsic Basicities and Hydrogen-Bonded Dimers of Nitrogen Heterocyclics and Nucleic Bases," Journal of the American Chemical Society, Vol. 101, 1979, pp. 2396-2403. doi:10.1021/ja00503a027

[12] D. A. Dixon and S. G. Lias, In: J. F. Liebman and A. Greenberg, Eds., Molecular Structure and Energetics, Vol. 2, Physical Measurements, VCH, Deereld Beach, FL, 1987. 
[13] L. A. Curtiss, K. Raghavachari and P. A. Pople, "Gaussian-2 Theory Using Reduced Moller-Plesset Orders," Journal of Chemical Physics, Vol. 98, No. 2, 1993, pp. 1293-1298. doi:10.1063/1.464297

[14] J. E. Del Bene, "Molecular Orbital Study of the Protonation of DNA Bases," The Journal of Physical Chemistry, Vol. 87, 1983, pp. 367-371. doi:10.1021/j100225a040

[15] B. J. Smith and L. Radom, "Calculation of Proton Affinities Using the G2(MP2,SVP) Procedure," The Journal of Physical Chemistry, Vol. 99, No. 17, 1995,pp. 6468-6471. doi:10.1021/j100017a028

[16] B. S. Jursic, "Density Functional Theory and Complete Basis Set $A b$ Initio Evaluation of Proton Affinity for Some Selected Chemical Systems," Journal of Molecular Structure: THEOCHEM, Vol. 487, No. 1, 1999, pp. 193203. doi:10.1016/S0166-1280(99)00154-2

[17] S. Hammerum, "Heats of Formation and Proton Affinities by the G3 Method," Chemical Physics Letters, Vol. 300, No. 3-4, 1999, pp. 529-532. doi:10.1016/S0009-2614(98)01439-0

[18] W. J. Hehre, L. Radom, P. V. R. Schleyer and J. A. Pople, "Ab Initio Molecular Orbital Theory," John Willey and Sons, New York, 1986.

[19] J. K. Labanowskiy, R. A. Hill, D. J. Heisterbergy, D. D. Miller, C. F. Bender and J. W. Andzelm, "Proton Affinities Calculated by Traditional Ab Initio Approaches and by Density Functional Methods,"

http://www.ccl.net/cca/documents/proton-affinity/affiniti es.pdf

[20] J. L. Ozment and A. M. Schmiedekamp, "Proton Affinities of Molecules Containing Nitrogen and Oxygen: Comparing $\mathrm{Ab}$ Initio and Semiempirical Results to Experiments," International Journal of Quantum Chemistry, Vol. 43, No. 6, 1992, pp. 783-800. doi:10.1002/qua.560430606

[21] M. Eckert-Maksic, M. Klessinger and Z. B. Maksic, "Theoretical Calculations of Proton Affinities in Phenol," Chemical Physics Letters, Vol. 232, No. 5, 1995, pp. 472478. doi:10.1016/0009-2614(94)01383-7

[22] N. Russo, M. Toscano, A. Grand and T. Mineva, "Proton Affinity and Protonation Sites of Aniline. Energetic Behavior and Density Functional Reactivity Indices," The Journal of Physical Chemistry A, Vol. 104, No. 17, 2000, pp. 4017-4021. doi:10.1021/jp991949e

[23] R. Margabandu and K. Subramani, "Comparative Study of Various Quantum Mechanical Descriptors for Prediction of Ionization Constant (pKa) of Substituted Anilines," International Journal of ChemTech Research, Vol. 2, No. 3, 2010, pp. 1507-1513.

[24] R. W. Taft, M. Taagepera, J. L. M. Abboud, J. F. Wolf, D. J. DeFrees, W. J. Hehre, J. E. Bartmess and Jr. R. T. McIver, "The Separation of Polarizability and Inductive Effects in Gas- and Solution-Phase Proton-Transfer Equilibriums," Journal of the American Chemical Society, Vol. 100, No. 24, 1978, pp. 7765-7767. doi:10.1021/ja00492a075

[25] Z. B. Maksic and R. Vianello, "Quest for the Origin of basicity: Initial vs Final State Effect in Natural Nitrogen Bases," The Journal of Physical Chemistry A, Vol. 106, No. 2, 2002, pp. 419-430. doi:10.1021/jp013296j

[26] P. Perez, A. Toro-Labbe and R. Contreras, "A Semiquantitative Description of Electrostatics and Polarization Substituent Effects: Gas-Phase Acid-Base Equilibria as Test Cases," The Journal of Physical Chemistry A, Vol. 104, No. 51, 2000, pp. 11993-11998. doi:10.1021/jp0025734

[27] P. Geerlings, F. De Proft and W. Langenaeker, "Conceptual Density Functional Theory," Chemical Reviews, Vol. 103, 2003, pp. 1793-1873. doi:10.1021/cr990029p

[28] M. Berkowitz, S. K. Ghosh and R. G. Parr, "On the Concept of Local Hardness in Chemistry," Journal of the American Chemical Society, Vol. 107, 1985, pp. 68116814. doi:10.1021/ja00310a011

[29] S. K. Ghosh, M. Berkowitz and R. G. Parr, "Transcription of Ground-State Density-Functional Theory into a Local Thermodynamic," Proceedings of the National Academy of Sciences, Vol. 81, No. 24, 1984, pp. 80288031. doi:10.1073/pnas.81.24.8028

[30] C. Hansch and A. Leo, "Substituent Constants for Correlation Analysis in Chemistry and Biology," John Wiley \& Sons, New York, 1979.

[31] M. V Putz, N. Russo and E. Sicilia, "Atomic Radii Scale and Related Size Properties from Density Functional Electronegativity Formulation," The Journal of Physical Chemistry A, Vol. 107, 2003, pp. 5461-5465. doi:10.1021/jp027492h

[32] M. V. Putz, N. Russo and E. Sicilia, "About the Mulliken Electronegativity in DFT," Theoret Chim Acta, Vol. 114, 2005, pp. 38-45. doi:10.1007/s00214-005-0641-4

[33] M. V. Putz, "Systematic Formulations for Electronegativity and Hardness and Their Atomic Scales within Density Functional Softness Theory," International Journal of Quantum Chemistry, Vol. 106, No. 2, 2006, pp. 361-389. doi:10.1002/qua.20787

[34] M. V. Putz, "Semi Classical Electronegativity and Chemical Hardness," Journal of Theoretical and Computational Chemistry, Vol. 6, No. 1, 2007, pp. 33-47.

[35] M. V. Putz, "Density Functionals of Chemical Bonding," International Journal of Molecular Sciences, Vol. 9, No. 6, 2008, pp. 1050-1095.

[36] M. V. Putz, "Electronegativity: Quantum Observable," International Journal of Quantum Chemistry, Vol. 109, No. 4, 2009, pp. 733-738. doi:10.1002/qua.21957

[37] L. Tarko and M. V. Putz, "On Electronegativity and Chemical Hardness Relationships with Aromaticity," Journal of Mathematical Chemistry, Vol. 47, No. 1, 2010, pp. 487-495. doi:10.1007/s10910-009-9585-6

[38] M. V. Putz, "Chemical Action and Chemical Bonding," Journal of Molecular Structure: THEOCHEM, Vol. 900 , No. 1-3, 2009, pp. 64-70. doi:10.1016/j.theochem.2008.12.026

[39] R. G. Parr, R. A. Donnelly, M. Levy and W. E. Palke, "Electronegativity: The Density Functional Viewpoint," 
Journal of Chemical Physics, Vol. 68, No. 8, 1978, pp. 3801-3807. doi:10.1063/1.436185

[40] R. G. Parr and R. G. Pearson, "Absolute Hardness: Companion Parameter to Absolute Electronegativity," Journal of the American Chemical Society, Vol. 105, No. 26, 1983, pp. 7512-7516. doi:10.1021/ja00364a005

[41] R.G. Parr and W. Yang, "Density Functional Approach to the Frontier-Electron Theory of Chemical Reactivity," Journal of the American Chemical Society, Vol. 106, No. 14, 1984, pp. 4049-4050. doi:10.1021/ja00326a036

[42] W. Yang and R. G. Parr, "Hardness, Softness, and the Fukui Function in the Electronic Theory of Metals and Catalysis," Proceedings of the National Academy of Sciences, Vol. 82, No. 20, 1985, pp. 6723-6726. doi:10.1073/pnas.82.20.6723

[43] R. G. Parr and W. Yang, "Density Functional Theory of Atoms and Molecules," Oxford University Press, New York, 1989.

[44] R. G. Parr, L. V. Szentpaly and S. Liu, "Electrophilicity Index," Journal of the American Chemical Society, Vol. 121, No. 9, 1999, pp. 1922-1924. doi:10.1021/ja983494x

[45] D. C. Ghosh, "A Theorrtical Study of Some Selected Molecules and Their Protonation by the Application of CNDO Method," Premchand Roychand Research Studentship Award, University of Calcutta, 1976.

[46] T. Chakraborty and D. C. Ghosh, "Computation of the Atomic Radii through the Conjoint Action of the Effective Nuclear Charge and the Ionization Energy," Molecular Physics, Vol. 108, No. 16, 2010, pp. 2081-2092.

[47] B. E. Mills, R. L. Martin and D. A. Shirley, "Further Studies of the Core Binding Energy-Proton Affinity Correlation in Molecules," Journal of the American Chemical Society, Vol. 98, No. 9, 1976, pp. 2380-2385. doi:10.1021/ja00425a002

[48] L. L. Lohr, "Protonic Counterpart of Electronegativity as an Organizing Principle for Acidity and Basicity," The Journal of Physical Chemistry, Vol. 88, 1984, pp. 36073611. doi:10.1021/j150660a046

[49] R. G. Pearson, "Absolute Electronegativity and Hardness Correlated with Molecular Orbital Theory," Proceedings of the National Academy of Sciences, Vol. 83, No. 22, 1986, pp. 8440-8441. doi:10.1073/pnas.83.22.8440

[50] P. Chaquin, "Absolute Electronegativity and Hardness: An Analogy with Classical Electrostatics Suggests an Interpretation of the Parr 'Electrophilicity Index' as a 'Global Energy Index' Leading to the 'Minimum Electrophilicity Principle," Chemical Physics Letters, Vol. 458, 2008, pp. 1439-1444.

[51] S. Noorizadeh, "Is There a Minimum Electrophilicity Principle in Chemical Reactions?" Chinese Journal of Chemistry, Vol. 27, 2007, pp. 1439-1444. doi:10.1002/cjoc.200790266

[52] N. Islam and D. C. Ghosh, "A New Algorithm for the Evaluation of Equilibrium Inter nuclear Bond Distance of Heteronuclear diatomic Molecule Based on the Hardness Equalization Principle," The European Physical Journal D-Atomic, Molecular, Optical and Plasma Physics, Vol.
61, No. 2, 2010, pp. 341-348.

[53] N. Islam and D. C. Ghosh, "A New Radial Dependent Electrostatic Algorithm for the Evaluation of the Electrophilicity Indices of the Atoms," International Journal of Quantum Chemistry, Vol. 111, No. 14, 2010, pp. 35563564. doi:10.1002/qua.22861

[54] N. Islam and D. C. Ghosh, "Determination of Some Descriptors of the Real World Working on the Fundamental Identity of the Basic Concept and the Origin of the Electronegativity and the Global Hardness of Atoms. Part 2: Computation of the Dipole Moments of Some Heteronuclear Diatomics," International Journal of Quantum Chemistry, Vol. 111, No. 12, 2010, pp. 2802-2810. doi:10.1002/qua.22651

[55] N. Islam and D. C. Ghosh, "Evaluation of Global Hardness of Atoms Based on the Commonality in the Basic Philosophy of the Origin and the Operational Significance of the Electronegativity and the Hardness. Part I. The Gordy's Scale of Electronegativity and the Global Hardness," European Journal of Chemistry, Vol. 1, No. 2, 2010, pp. 83-89.

[56] N. Islam and D. C. Ghosh, "Charge transfer associated with the physical process of hardness equalization and the chemical event of the molecule formation and the dipole moments," International Journal of Quantum Chemistry, 111, No. 12, 2010, pp. 2811-2819.

[57] N. Islam and D. C. Ghosh, "Determination of Some Descriptors of the Real World Working on the Fundamental Identity of the Basic Concept and the Origin of the Electronegativity and the Global Hardness of Atoms, Part 1: Evaluation of Internuclear Bond Distance of Some Heteronuclear Diatomics," International Journal of Quantum Chemistry, 2010, in Press. doi:10.1002/qua.22500

[58] N. Islam and D. C. Ghosh, "A Quest for the Algorithm for Evaluating the Molecular Hardness," International Journal of Quantum Chemistry, Vol. 111, No. 9, 2010, pp. 1931-1941. doi:10.1002/qua

[59] N. Islam and D. C. Ghosh, "Whether There Is a Hardness Equalization Principle Analogous to the Electronegativity qualization Principle - A Quest," International Journal of Quantum Chemistry, Vol. 111, No. 9, 2010, pp. 19611969. doi:10.1002/qua.22508

[60] N. Islam and D. C. Ghosh, "Whether Electronegativity and Hardness Are Manifest Two Different Descriptors of the One and the Same Fundamental Property of AtomsA Quest," International Journal of Quantum Chemistry, Vol. 111, No. 1, 2009, pp. 40-51. doi:10.1002/qua.22415

[61] N. Islam and D. C. Ghosh, "A New Algorithm for the Evaluation of the Global Hardness of Poly Atomic Molecules," Molecular Physics, 2011, Accepted.

[62] E. P. L. Hunter and S. G. Lias, "Evaluated Gas Phase Basicities and Proton Affinities of Molecules: An update," Journal of Physical and Chemical Reference Data, Vol. 27, No. 3, 1998, pp. 413-656. doi:10.1063/1.556018

[63] National Institute of Standards and Technology. http://webbook.nist.gov/chemistry/pa-ser.html.

[64] T. Wróblewski, L. Ziemczonek, A. M. Alhasan and G. P. 
Karwasz.

http://www.fizyka.umk.pl/ karwasz/.../2007_Ab_initio_and _density_functional.pdf.

[65] S. G. Lias, J. E. Bartmess, J. F. Liebman, J. L. Holmes, R. D. Levin and W. G. Mallard, "Gas-Phase Ion and Neutral Thermochemistry," Journal of Physical and Chemical Reference Data, Vol. 17, Suppl. 1, 1988, pp. 1-861. doi:10.1063/1.555819

[66] PQSMol 1.2-20-win, Parallel Quantum Solutions, LLC. http://www.pqs-chem.com.

[67] C. Nantasenamat, C. Isarankura-Na-Ayudhya, T. Naenna and V.Prachayasittikul, "A Practical Overview of Quantitative Structure-Activity Relationship," EXCLI Journal, Vol. 8, 2009, pp. 74-88.

[68] MINITAB, a Statistical Software of STATSOFT Inc U.S.A. 